\title{
Spontaneous Rapture of an Incisional Hernia: A Case Report.
}

\section{Mwesigye}

Mubende Regional Hospital, Uganda

Correspondence to: Dr. Ismail Mwesigye, Email: ahlazhar@gmail.com

An incisional hernia develops in the scar of a surgical incision. Rarely, a particularly thin-walled large incisional hernia may actually ulcerate at its fundus so that omentum protrudes or there is even the development of an intestinal fistula. Spontaneous rupture of an abdominal hernia is very rare and usually occurs in incisional or recurrent groin hernia'. Von Helwig ${ }^{2}$ in 1958 reported 47 cases of spontaneous exteriorization of bowel through abdominal hernia, out of these 17 cases were through incisional hernia while others were through inguinal, femoral, umbilical and epigastric hernias. The site of rupture is different in diverse studies. Hartley $^{3}$ and Hamilton 4 reported rupture through thr lower midline incision while Aggarwal $^{5}$ found herniation after upper abdominal surgery following perforated duodenal ulcer.

\section{Case Report}

A 30-year-old lady was under treatment in the outpatient department for her incisional hernia following midline caesarean section 5 years earlier. The hernia was large and protruding through a defect of $8 \times 6 \mathrm{~cm}$ in the lower abdomen. The skin over the hernia sac was atrophic, depigmented and thinned out, but there was no ulceration. She was planned for mesh repair but she declined the operation because inability to afford the cost a mesh. She presented in casualty with a loop of bowel protruding through a defect of $3 \times 2 \mathrm{~cm}$ in the hernia sac following a severe bout of cough (Figure 1). Around $3 \mathrm{ft}$ of bowel was outside which could not be replaced; it was healthy but slightly edematous. Immediate surgery was planned and the patient was shifted to Emergency OT.

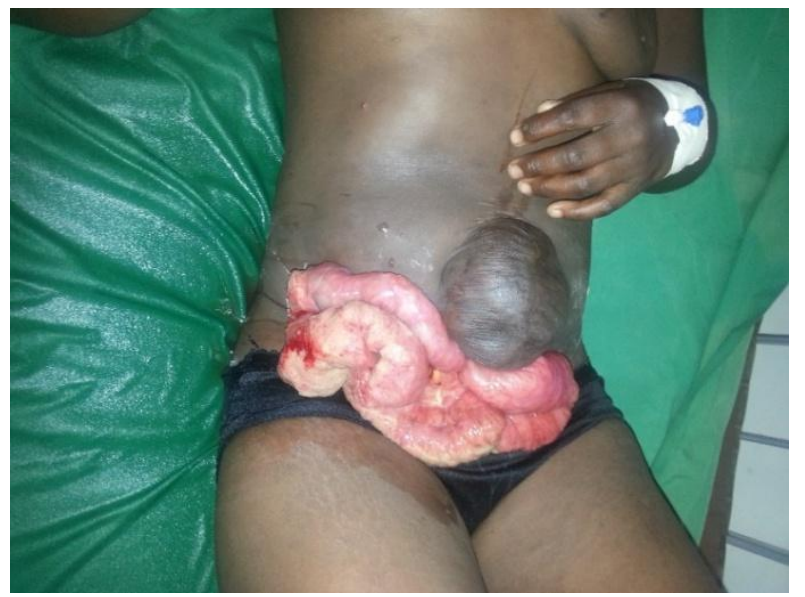

Figure 1: Bowel Protruding through the Defect in the Hernia Sac

At operation, the defect was enlarged and bowel repositioned into the peritoneal cavity. No adhesions were found and no suture was found which made us think that probably an absorbable suture was used during closure of rectus sheath. After removing all the atrophic and 
scarred skin, repair was done by Moloneydarn technique since mesh repair was beyond our reach. The patient was put on prophylactic antibiotics for three days and she was discharged home on tenth day after removing the stitches. The wound healed well without any infection. She is still being followed up now four months so far without any recurrence.

\section{Discussion}

Spontaneous rupture of abdominal hernia is a rare event which can affect any abdominal hernia but is more commonly reported in incisional hernia ${ }^{2,6,7}$. This rupture may be sudden following any event which can increase the intrabdominal pressure like coughing or lifting a heavy weight, or it may be gradual after developing an ulcer at the fundus of the sac ${ }^{2,4}$. In both situations the main reason is weak and thinned out atrophic skin. In our case, rupture of the hernial sac occurred because of sudden increase in intrabdominal pressure due to excessive coughing. Various factors which can contribute to the rupture of a hernia are friction by the patient's external corset or abdominal support, thin atrophic skin, lack of any adhesions between bowel and sac, allowing the bowel to act as a hammer-head upon the skin $^{3}$. Eventration of bowel or omentum demands emergency operation and this may or may not be combined with an attempt of definitive hernia repair. If the bowel can be reduced easily and the defect readily closed, it has been recommended that primary repair be carried out, but if strangulation occurs or bowel resection is required the primary repair is hazardous 3,5 .

\section{Conclusion}

Spontaneous rupture of abdominal hernia is a very rare complication. It usually occurs in cases of incisional hernia. This rupture may be gradual because of ulceration of the overlying skin or sudden due to any event which can increase the intrabdominal pressure. These cases should be managed by primary repair if there is no gangrenous segment and the contamination is minimal or by delayed repair if there is gross contamination and resection and anastomosis is required.

\section{References}

1. Michael J. Zinner, Seymour I. Schwartz, Harold Ellis. Incisions, closures, and management of the Wound. Maingot's abdominal surgery. 10th edit. USA: Appleton and Lange, 1997, vol 1: 423

2. Von Helwig H. Uber Sonenannte Spontaneous rupture von hernien. Schweiz.med.wschr. 1958: 88; 662-66.

3. Hartely R C. Spontaneous rupture of incisional hernia. Br. J surg. 1961; 49: 61718

4. $\quad$ Hamilton R W. Spontaneous rupture of incisional hernia. Br. J Surg. 1966; 33: 477-79

5. Aggarwal P K. Spontaneous rupture of incisional hernia. Br. J ClinPract. 1986 oct; 40(10) 443-4

6. Singla S L, Kalra U, Singh B, Naraula S, Dahiy P. Ruptured incisional hernia. Trop Doct.1997; Apr: 27(2): 112-3

7. Ogundiran TO, Ayantunde AA, Akute 00. Spontaneous rupture of incisional hernia--a case report. West Afr J Med. 2001; Apr-Jun;20(2):176-8. 